\title{
Influence of polymer additives on rheological properties of heavy high-viscosity \\ oil
}

\author{
P. Topilnytskyy ${ }^{(1)}$, V.Romanchuk ${ }^{(2)}, \underline{\text { T.Yarmola }}^{(3)}$
}

1. Department of Chemistry and Technology of Petroleum, Lviv Polytechnic National University, Str. St. Bandery, 12, Lviv, 79013, Ukraine, E-mail: topoil@ polynet.lviv.ua

2. Department of Chemistry and Technology of Petroleum, Lviv Polytechnic National University, Str. St. Bandery, 12, Lviv, 79013, Ukraine, E-mail: vikarom318@gmail.com

3. Department of Chemistry and Technology of Petroleum, Lviv Polytechnic National University, Str. St. Bandery, 12, Lviv, Ukraine, 79013,E-mail: yarmolatetana@gmail.com

\begin{abstract}
The rheological properties of high-viscosity oils from 2 wells of the Yablunivske field (Poltava region, Ukraine). To improve the rheological properties of the oil, polymer additives were added and the dynamic viscosity and shear stress. The addition of polymer additives has been found to improve the rheological properties of heavy oils and reduce kinematic viscosity, which is of practical importance for facilitating their extraction and transportation.
\end{abstract}

Key words - heavy oil, polymer additives, oil transportation, rheological properties of oil.

\section{Introduction}

To date, due to the steady reserves depletion of light, low-viscosity oils, there is an urgent necessity to introduce into operation the fields of heavy reserves, such as high-viscosity oils and natural bitumen. Oil fields of this type are usually characterized by high concentration of metals and sulfur compounds, high values of density, viscosity and coking ability due to the high content of asphaltenes and resins [1]. Rheological properties are important parameters of oil field products. The study of rheological properties allows to substantiate and implement effective complex technologies to increase oil recovery during the operation of certain facilities. The peculiarity of the rheological properties of heavy oils is the variability of their dynamic viscosity, which depends on the applied shear stress and flow rate. According to the experts, the largest reserves of heavy highviscosity oil are located in Canada, Venezuela, the Russian Federation. Approximately $2 \%$ of the world's reserves of high-viscosity oil are concentrated in Ukraine.The largest of Dnieper-Donetsk basin - Yablunivske gas condensate field. The difficulties of operation of the Yablunivsky gas condensate field - is located in Poltava region, require its rational development, and for the extraction and transportation of reserves it is necessary to determine the rheological properties of oil. There are many ways to process oil to reduce its viscosity. And one of them is the addition of polymer additives. [2].Chemical reagents used to reduce the oil viscosity provide the conditions that prevent the formation of collective colloidal structures, reduce gravity between colloidal particles and preserve the colloidal component in the form of single particles. The introduced synthetic polymer products are able to change oil viscosity and shear stress. Usually esters, alcohols and various polymers are used [3].

The aim of research: to determine the effect of polymer additives on the rheological properties of heavy highly resinous oil, to reduce the oil viscosity and to find ways of heavy oil processing.

\section{Experimental}

To study the rheological properties we used the high-viscosity oil of Yablunivske field from two wells:sample 1 - oil with a density of $977 \mathrm{~kg} / \mathrm{m}^{3}$ at $20{ }^{\circ} \mathrm{C}$ from well 88 , sample 2 - oil with a density of $972 \mathrm{~kg} / \mathrm{m}^{3}$ at $20{ }^{\circ} \mathrm{C}$ from well 337 .

To improve the rheological properties, polyethylene glycol (PEG, molecular weight 400, density $\left.\mathrm{d}_{20}=1130 \mathrm{~kg} / \mathrm{m}^{3}\right)$, polypropylene glycol $\left(\mathrm{PPG}\right.$, molecular weight 400 , density $\mathrm{d}_{20}=1010$ 
$\mathrm{kg} / \mathrm{m}^{3}$ ) and demulsifier of PM brand (content of ethylene and propylene oxides copolymer is $70 \%$, density $1000 \mathrm{~kg} / \mathrm{m}^{3}$ ) were added separately in the amount of $3 \%$ per sample. Before adding the oil was heated to $50{ }^{\circ} \mathrm{C}$. The dynamic viscosity and shear stress of samples from both wells were investigated at 20,30 , and $40{ }^{\circ} \mathrm{C}$. After addition of polymer additives the measurements were carried out again. The most important physico-chemical properties of oils are presented in Table 1.

Table 1 .

Physico-chemical properties of oil

\begin{tabular}{|l|c|c|}
\hline \multicolumn{1}{|c|}{ Property } & Sample 1 & Sample 2 \\
\hline Density at $20{ }^{\circ} \mathrm{C}, \mathrm{kg} / \mathrm{m}^{3}$ & 977 & 972 \\
\hline Kinematic viscosity at $50{ }^{\circ} \mathrm{C}, \mathrm{mm}^{2} / \mathrm{s}$ & 326 & 386 \\
\hline Coking ability, \% & 9.8 & 7.3 \\
\hline Pour point, ${ }^{\circ} \mathrm{C}$ & 14 & 8 \\
\hline Content of water, \% & 4.9 & 5.6 \\
\hline Content of chlorides, $\mathrm{mg} / \mathrm{dm}^{3}$ & 2900 & 6280 \\
\hline Content of sulfurous resins, vol \% & 16.9 & 14.8 \\
\hline
\end{tabular}

The addition of polymer additives significantly affects the rheological properties of oils. The shear stress of the sample 1 at 20,30 and $40{ }^{\circ} \mathrm{C}$ is $1338.40,564.03$ and $261.94 \mathrm{~Pa}$, respectively. When polypropylene glycol is added, the shear stress is 1070.7, 398.33 and 229.44 PA, respectively. The addition of polyethylene glycol reduces the shear stress to $873.13,481.18$ and 2176.69 Pa, respectively. And the addition of the PM demulsifier to the sample 1 reduces the shear stress to $924.11 \mathrm{~Pa}$ at $20{ }^{\circ} \mathrm{C}$, and to 200.76 and $97.19 \mathrm{~Pa}$ at higher temperatures, respectively.

The addition of polymer additives to sample 2 also significantly affects the shear stress. For this sample, the addition of polypropylene glycol shows slightly better results. The shear stress at the above mentioned temperatures decreases to 4397.5, 1937.45 and $828.52 \mathrm{~Pa}$, respectively. The addition of polyethylene glycol and PM demulsifier also reduces the shear stress. The addition of polymer additives to high-viscosity oils also has a significant effect on reducing the dynamic viscosity. Thus, the dynamic viscosity of sample 1 at the temperatures of 20,30 and $40{ }^{\circ} \mathrm{C}$ is 2.961 , 1.248 and $0.579 \mathrm{~Pa} \cdot \mathrm{s}$, respectively. When adding PPG, PEG and PM demulsifier the value decreases by $20-35 \%$ at a shear rate of $452 \mathrm{~s}^{-1}$. For sample 2, the dynamic viscosity is $13.666,5.781$ and $2.51 \mathrm{~Pa} \cdot \mathrm{s}$, respectively. When PPG and PEG are added, the dynamic viscosity decreases insignificantly, but the addition of PM demulsifier reduces this value by $25 \%$.

\section{Conclusions}

The addition of polymer additives PEG, PPG, copolymers of ethylene oxide and propylene to high-viscosity oils significantly reduces the viscosity, shear stress and will help to reduce energy consumption in oil production and transportation.

\section{References}

1. Topilnytskyy, P., Paiuk, S., Stebelska, H., Romanchuk, V., \& Yarmola, T. (2019). Technological features of high-sulfur heavy crude oils processing. Chemistry \& Chemical Technology, 4 (13), 2019, (4), 503-509.

2. Pyshyev, S., Gunka, V., Grytsenko, Y., Shved, M., \& Kochubei, V. (2017). Oil and gas processing products to obtain polymers modified bitumen. International Journal of Pavement Research and Technology, 10(4), 289-296.

3. Topilnytskyy, P., Romanchuk, V., Boichenko, S., \& Golych, Y. (2014). Physico-chemical properties and efficiency of demulsifiers based on block copolymers of ethylene and propylene oxides. 